\title{
Ю.В. Симачев
}

Национальный исследовательский университет «Высшая школа экономики», Москва

\section{М.Г. Кузык}

Национальный исследовательский университет «Высшая школа экономики»;

Межведомственный аналитический центр, Москва

\section{Е.В. Погребняк}

Внешэкономбанк, Москва

\section{Промышленная политика федерального уровня: базовые модели и российская практика ${ }^{1}$}

Аннотация. В статье проведена типологизация российской промышленной политики 2000-х годов, рассматривается ряд крупных инициатив в данной сфере, обсуждаются изменения подходов государства к ее проведению. Отмечена склонность государства к реализации вертикальной политики, при этом горизонтальные механизмы нередко вертикализуются под влиянием традиционных групп интересов. Отмечается активное создание государством новых механизмов поддержки организаций и отраслей, особенно характерное для кризисных периодов, что однако почти не сопровождается отказом от некоторых действующих неэффективных инструментов. Показано, что государство чаще обращалось к политике догоняющего развития. Наряду с этим есть предпосылки к интенсификации усилий государства проводить политику опережающего развития. В этом случае потребуется своевременно перейти от достижения точечных результатов на уровне отдельных компаний к созданию условий для быстрого распространения новых технологий и перспективных бизнес-моделей, что, в свою очередь, потребует перехода от культуры проектного управления к культуре качественного исполнения рутин.

Ключевые слова: промышленная политика, структурные изменения, государственная поддержка, догоняющее развитие, опережающее развитие.

Классификация JEL: L52, O25.

DOI: $10.31737 / 2221-2264-2018-39-3-8$

Промышленная политика традиционно является предметом острых дискуссий, при этом сегодня единства взглядов нет даже в отношении определения самого понятия такой политики. В данной статье мы исходим из следующего, широкого определения промышленной политики.

Промышленная политика представляет собой любые действия государства, направленные на улучшение условий ведения бизнеса и (или) изменение структуры экономической активности в секторах и (или) технологических областях и призванные обеспечить улучшение перспектив экономического роста и (или) повышения благосостояния, которое бы не произошло в отсутствие государственного вмешательства (на основе (Pack, Saggi, 2006; Warwick, 2013)).

Ключевым сущностным признаком любой промышленной политики является фокусное воздействие на отдельные отрасли или сферы деятельности. Такое воздействие может быть результатом применения государством селективных мер, изначально направленных на определенные сектора либо группы компаний, в таких случаях говорят о вертикальном характере политики, либо обеспечиваться неоднородностью воздействия применяемых инструментов на разные сектора и сферы. Подобного рода политику принято относить к горизонтальному типу (Gual, Jodar, 2006; Кузнецов, Симачев, 2014).

При многообразии задач, решаемых национальными правительствами при помощи промышленной политики (Lin, 2012; Garcia Calvo, Coulter, 2017), можно выделить три ее базовые модели.

1. Компенсачионная политика направлена на предотвращение негативных структурных изменений, уже происходящих либо

\footnotetext{
1 Статья подготовлена по результатам исследовательского проекта НИУ ВШЭ «Структурные изменения в российской экономике и структурная политика» (https://www.hse.ru/data/2018/04/13/1150725828/Аналитический доклад по структурной политике.pdf).
} 
ожидаемых. Она может осуществляться как по отраслевому принципу, так и без привязки к конкретной сфере, однако является вертикальной, поскольку направлена четко определенному кругу адресатов. Зачастую, хотя и не всегда, такая политика имеет антикризисный характер и предполагает в большей степени не поддержку лидеров, а помощь отстающим.

2. Политика догоняющего развития призвана сократить отставание (как правило, технологическое) отдельных национальных производств, компаний или секторов. Как правило, такая политика имеет вертикальный либо смешанный характер и ориентирована на существующие компании, при отборе которых принимаются во внимание их текущее качество и перспективность.

3. Политика опережающего развития призвана обеспечить отдельным национальным компаниям (некоторым секторам) технологическое превосходство, как минимум, над большинством конкурентов и тем самым создать для них реальную возможность выйти на лидирующие позиции в мире. Опережающая политика в большинстве случаев не имеет четкой отраслевой привязки, она может быть реализована как вертикальными, так и горизонтальными мерами, нередко - абсолютно новыми и созданными специально для ее проведения.

В России накоплен немалый опыт проведения промышленной политики как в традиционных секторах, так и относительно новых областях и сферах: начиная с 2000 г. мы можем выделить по крайней мере восемь различных крупных инициатив государства в проведении активной промышленной политики (табл. 1).

В начале 2000-х годов на фоне проявления признаков восстановительного роста государство попробовало реализовать некоторые меры, направленные на диверсификацию российской экономики. Отметим, что на начальном этапе реализуемая политика имела мягкий, горизонтальный характер. Показательным примером здесь может служить первоначальная редакция федеральной целевой программы (ФЦП) «Электронная Россия (2002-2010 годы)», мероприятия которой были направлены на совершенствование законодательства и системы государственного регулирования в сфере информационнокомпьютерных технологий (ИКТ), развитие телекоммуникационной инфраструктуры, системы подготовки специалистов, создание условий для эффективного взаимодействия между органами государственной власти, бизнесом и населением на основе использования ИКТ ${ }^{2}$.

Примерно с середины 2000-х годов на фоне общего усиления роли государства в экономике произошла существенная активизация промышленной политики. Возросшие ресурсные возможности государства позволили нарастить объемы финансовой поддержки отраслей, распределяемой, в частности, посредством инструмента федеральных целевых программ (ФЦП), а также создать и капитализировать ряд крупных институтов развития (Симачев и др., 2014). При этом реализуемая политика имела преимущественно вертикальный характер - одним из ярких примеров такого рода может служить комплекс мер, направленных на развитие автомобильной промышленности. Вместе с тем государство отнюдь не отказалось и от горизонтальной политики, которая, однако, как правило, дополнялась вертикальными мерами: в частности, таким образом была организована политика в сфере развития наноиндустрии.

В условиях финансово-экономического кризиса конца 2008 - начала 2010-х годов промышленная политика стала более селективной. Основная часть принимавшихся мер была связана с компенсацией спада в наиболее уязвимых секторах и поддержкой отдельных компаний, банкротство которых могло повлечь значимые последствия, прежде всего - социальные. При этом существенная часть инструментов промышленной политики была связана с усилением государственного вмешательства в экономику - частный спрос замещался государственным, устанавливались протекцио-

\footnotetext{
2 Позднее данная программа стала более вертикальной и фактически была переориентирована на информатизацию сферы государственного управления.
} 


\begin{tabular}{|c|c|c|c|c|c|c|}
\hline & 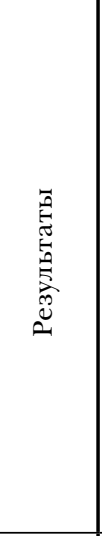 & 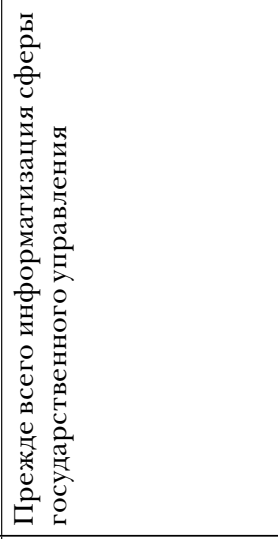 & 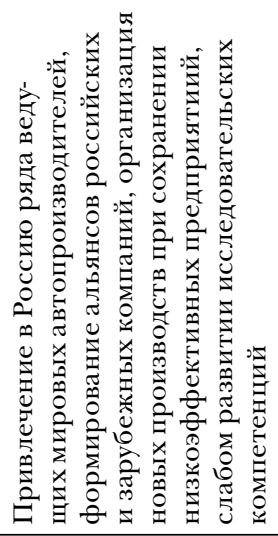 & 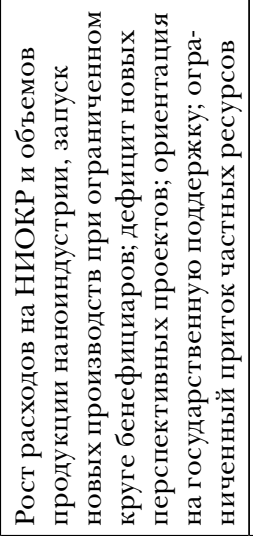 & 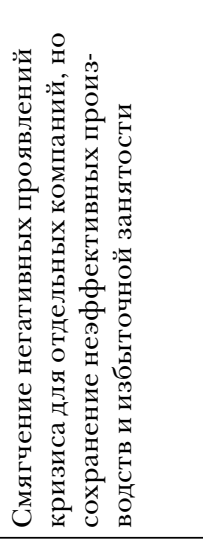 & 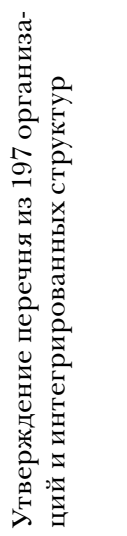 \\
\hline & 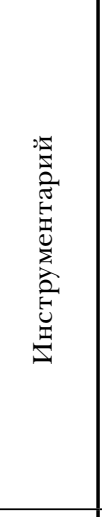 & 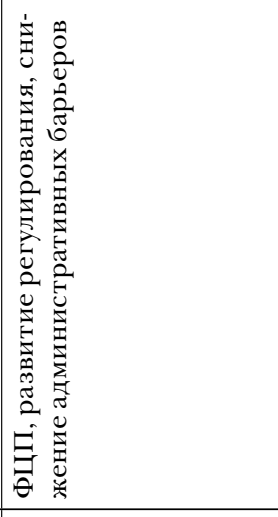 & 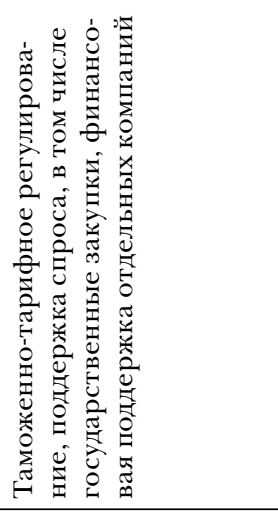 & 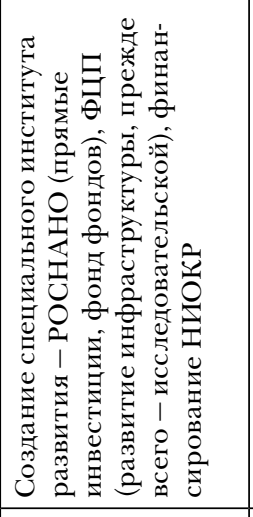 & 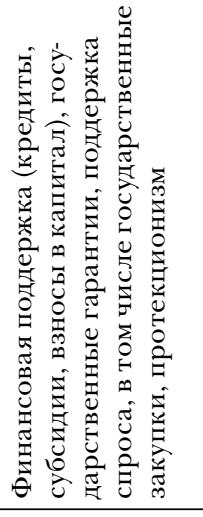 & 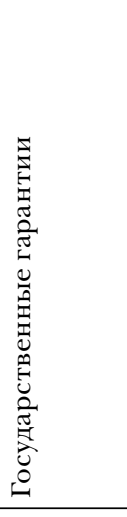 \\
\hline & 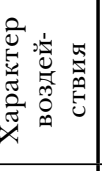 & 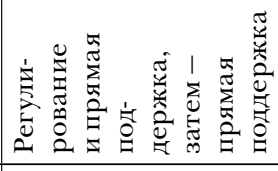 & 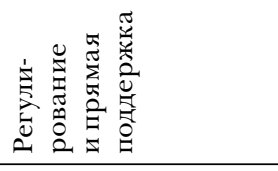 & 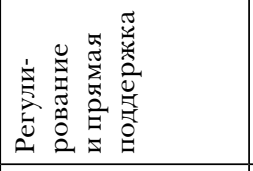 & 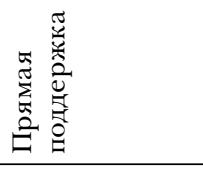 & \\
\hline & 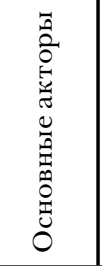 & 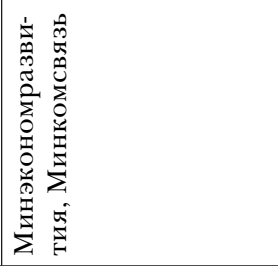 & 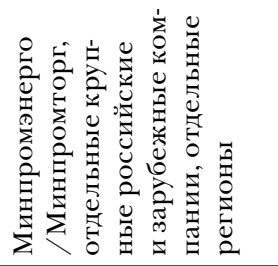 & 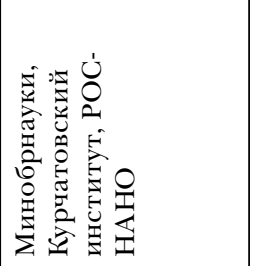 & 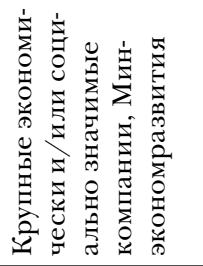 & \\
\hline & $\stackrel{\Xi}{\exists}$ & 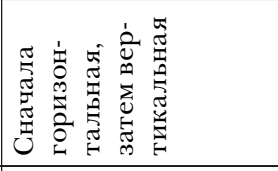 & 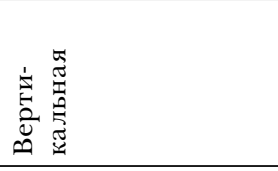 & 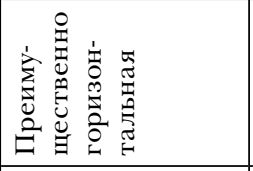 & 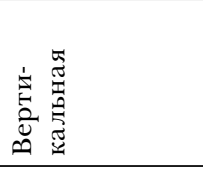 & \\
\hline & $\stackrel{f}{0}$ & 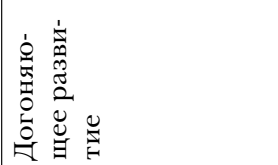 & 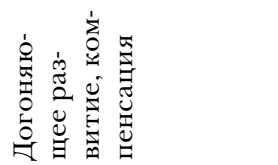 & 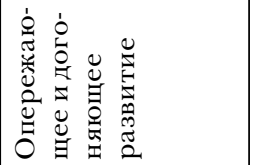 & 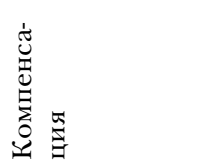 & \\
\hline & 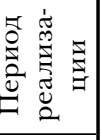 & :IJ $0 \mathrm{~L} 06-6006$ & I I $9006^{\circ}$ & I $\angle 006 د$ & :II L LOZ-6006 & 'I $\angle \mathrm{L} 0 \sigma^{\circ}$ \\
\hline & 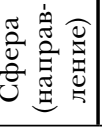 & $\begin{array}{c}\text { вио } \\
- \text { - }_{\mathbf{d}} \text { веннодцяәгє }\end{array}$ & $\begin{array}{c}\text { әинә } \\
\text {-odцәәгияожоця }\end{array}$ & видцวКтнионеН & \multicolumn{2}{|c|}{ 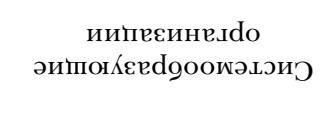 } \\
\hline
\end{tabular}




\begin{tabular}{|c|c|c|c|c|}
\hline 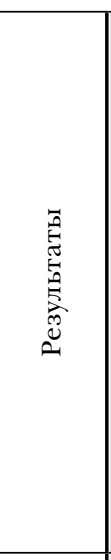 & 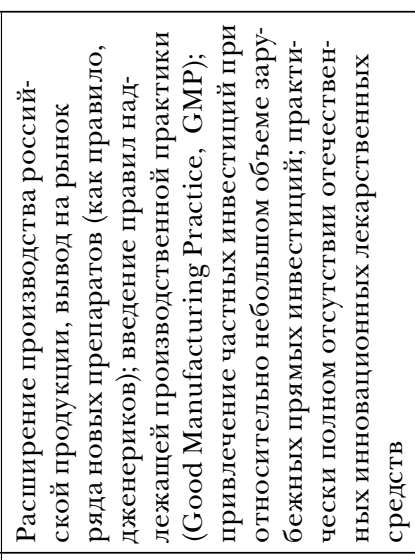 & 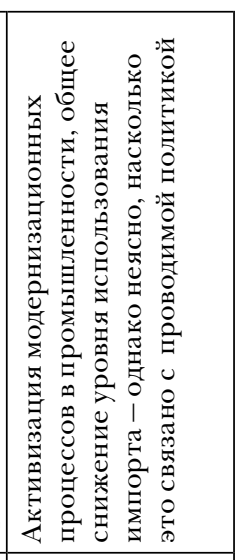 & 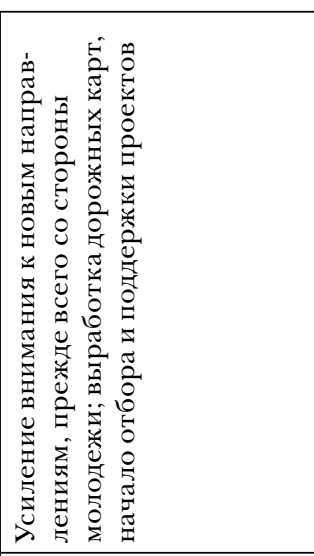 & 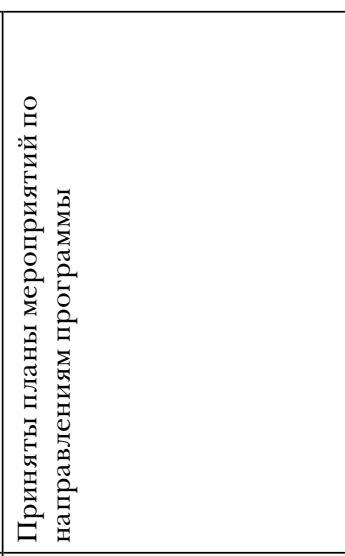 \\
\hline 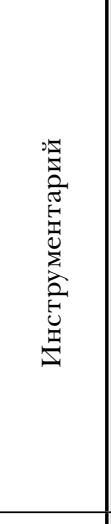 & 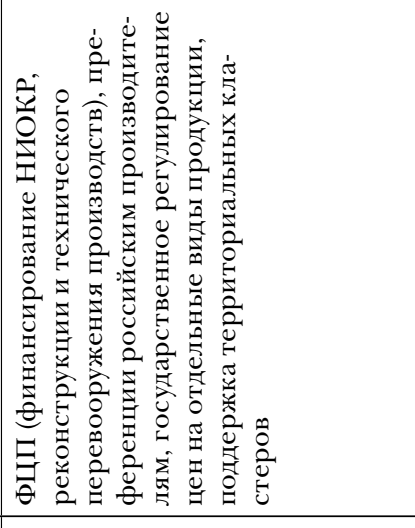 & 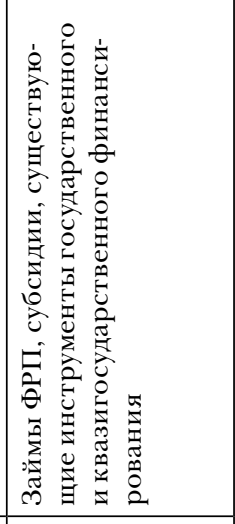 & 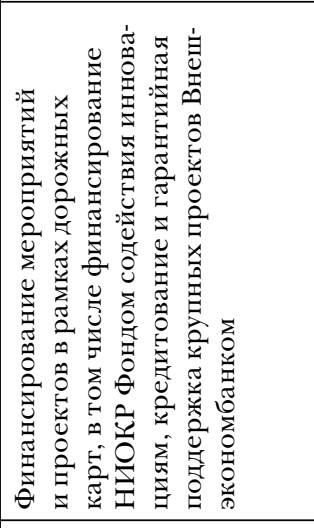 & 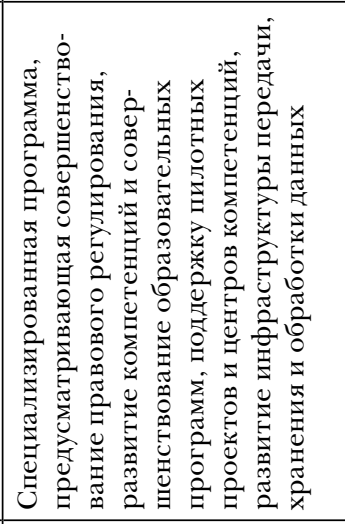 \\
\hline 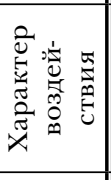 & 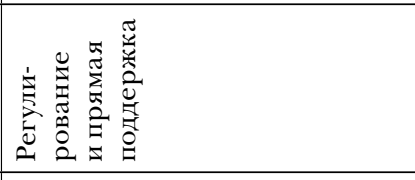 & 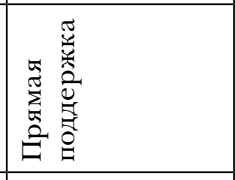 & 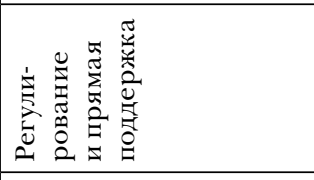 & 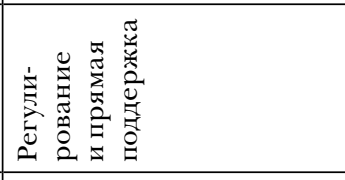 \\
\hline 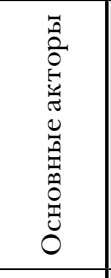 & 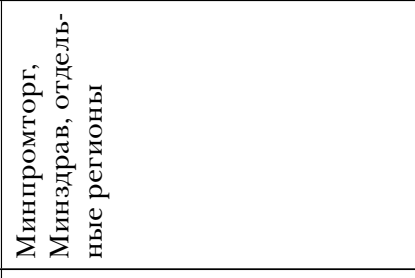 & 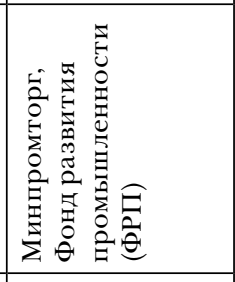 & 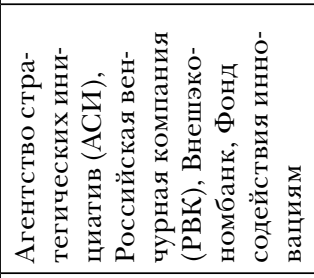 & 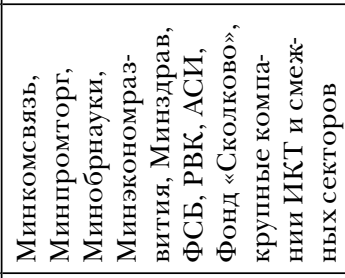 \\
\hline 量 & 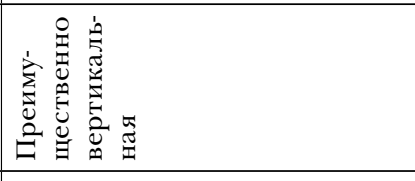 & 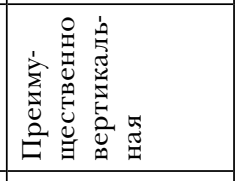 & 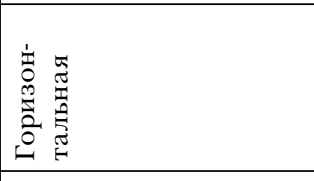 & 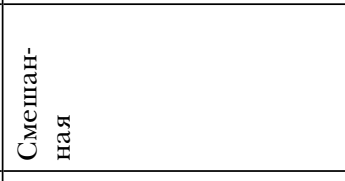 \\
\hline 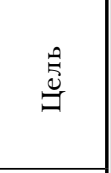 & 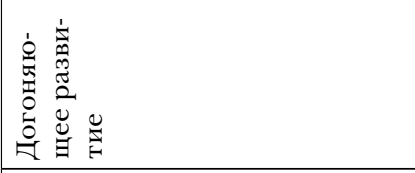 & 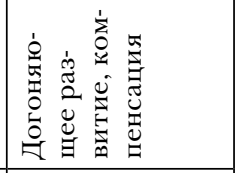 & 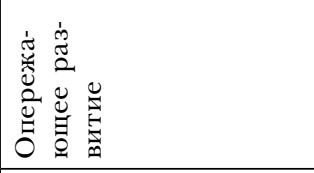 & 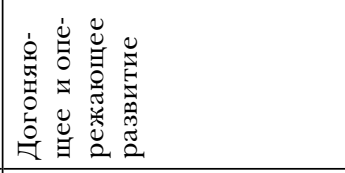 \\
\hline 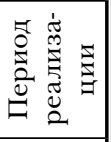 & د & 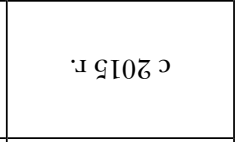 & ' & $\cdot \mathrm{x} \angle \mathrm{L} 0 \sigma^{\circ}$ \\
\hline 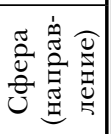 & $\begin{array}{c}\text { qLวоннәгпाчкодш } \\
\text { веяวәьицаәпекdе }\end{array}$ & 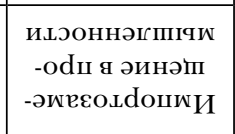 & $\begin{array}{c}\text { еяицеипини } \\
\text { еяวәьилогонхәц } \\
\text { енчгеноипен }\end{array}$ & $\begin{array}{l}\text { вяишонояє } \\
\text { веяодфиП }\end{array}$ \\
\hline
\end{tabular}


нистские барьеры в интересах отдельных секторов (Горст и др., 2009). Одним из типичных примеров промышленной политики в данный период являлась масштабная государственная поддержка системообразующих компаний, включенных в специально сформированный для этих целей перечень ${ }^{3}$.

С 2010 г., преодолев острую фазу кризиса, государство начало серьезно искать новые движущие силы для долгосрочного устойчивого роста. С 2014 г. значимые изменения в ландшафт проводимой политики внесло обострение внешнеполитической обстановки, повлекшее за собой двусторонние экономические ограничения. Вследствие этого реализуемая в настоящее время политика, как правило, либо имеет поисковый характер направлена на поиск новых рынков и технологических областей с большим потенциалом развития (Национальная технологическая инициатива), либо призвана повысить устойчивость экономики, в том числе в условиях возможного расширения санкций (стимулирование импортозамещения в ряде отраслей промышленности).

Итак, в рассматриваемый период (2000-2017 гг.) отношение государства к промышленной политике в целом и к практическим путям ее реализации в частности существенно (иногда - кардинально) менялось. Предпринимались попытки проводить как горизонтальную, так и вертикальную политику.

В течение всего этого периода происходило динамичное расширение инструментария промышленной политики. В результате сформирован широкий набор механизмов - от специальных программ, институтов развития и налоговых мер и до разнообразных объектов инфраструктуры, включая попытку воспроизвести в России опыт развития «Кремниевой долины» в рамках инновационного центра «Сколково» 4 .
В этой связи представляется важным отметить два обстоятельства.

1. Практика отказа от ранее инициированных в рамках промышленной политики механизмов и форм поддержки имела крайне ограниченный характер, хотя некоторые из них формально или фактически предполагали временный характер действия. А немногочисленные примеры прекращения использования отдельных мер поддержки обычно де-факто сопровождались их заменой на аналогичные или содержательно близкие механизмы.

2. Государство тяготеет к проведению вертикальной политики, связанной с использованием инструментов прямой поддержки крупных традиционных компаний. Такая политика позволяет органам власти снизить риски неэффективного использования ресурсов и получить более значимые результаты для отчетности. Следует также заметить, что многие направления и меры промышленной политики, обеспечивающие сколько-нибудь масштабные выгоды, либо изначально инициировались традиционными и мощными игроками и группами интересов, либо «приватизировались» ими в процессе использования ${ }^{5}$. Таким образом, даже изначально горизонтальные инициативы в последующем приобретали черты вертикальных.

Проецируя рассмотренные примеры промышленной политики на ранее представленные модели (табл. 2), обратим внимание на следующее.

Наиболее масштабной (c позиций задействованных ресурсов и инструментов) была компенсационная политика. В целом цели и управление такой политикой объективно являются наиболее ясными. Ключевой же недостаток данной политики заключается в том, что в направленности не на лучших и перспективных, а на нуждающихся и значимых, такая политика часто приводит к сохранению неэф-

\footnotetext{
3 Заметим, что в настоящее время практика поддержки системообразующих компаний возобновляется.

4 Более того, подобные попытки, весьма вероятно, будут продолжаться и в дальнейшем: в регионах будут создавать разного рода «технологические долины» - инновационные научно-технологические центры.

${ }^{5}$ Важно заметить, что такая ситуация характерна отнюдь не только для России, и в зарубежной практике бенефициарами мер и инструментов государственной политики, изначально не ориентированных на определенный круг адресатов, чаще всего становятся крупные, устойчивые и давно функционирующие на рынке компании (Rоdrik, 2004, 2008).
} 
Таблица 2

Типология российской промышленной политики

\begin{tabular}{|c|c|c|c|}
\hline $\begin{array}{c}\text { Тип } \\
\text { политики }\end{array}$ & $\begin{array}{c}\text { Компенсационная } \\
\text { политика }\end{array}$ & $\begin{array}{c}\text { Политика } \\
\text { догоняющего развития }\end{array}$ & $\begin{array}{c}\text { Политика } \\
\text { опережающего } \\
\text { развития }\end{array}$ \\
\hline $\begin{array}{l}\text { Стратегиче- } \\
\text { ская направ- } \\
\text { ленность }\end{array}$ & $\begin{array}{l}\text { Преодоление либо пре- } \\
\text { дотвращение негатив- } \\
\text { ных социально-экономи- } \\
\text { ческих изменений }\end{array}$ & $\begin{array}{l}\text { Ответ на текущие техно- } \\
\text { логические или экономи- } \\
\text { ческие вызовы }\end{array}$ & $\begin{array}{l}\text { Ответ на будущие техно- } \\
\text { логические, экономиче- } \\
\text { ские, социальные или } \\
\text { иные вызовы }\end{array}$ \\
\hline $\begin{array}{l}\text { Характер } \\
\text { политики }\end{array}$ & $\begin{array}{l}\text { Вертикальная - направ- } \\
\text { лена на конкретные ком- } \\
\text { пании }\end{array}$ & $\begin{array}{l}\text { Как правило, вертикаль- } \\
\text { ная или смешанная }\end{array}$ & $\begin{array}{l}\text { Горизонтальная, но тен- } \\
\text { денция трансформации } \\
\text { в вертикальную }\end{array}$ \\
\hline $\begin{array}{l}\text { Новизна } \\
\text { технологий }\end{array}$ & Не важна & $\begin{array}{l}\text { Средняя - чаще всего } \\
\text { технологии, известные } \\
\text { в мире, новые для Рос- } \\
\text { сии или компании }\end{array}$ & $\begin{array}{l}\text { Высокая - разработка } \\
\text { новых технологий }\end{array}$ \\
\hline $\begin{array}{l}\text { Круг } \\
\text { участников }\end{array}$ & $\begin{array}{l}\text { Достаточно широкий, } \\
\text { но включающий суще- } \\
\text { ствующие крупные } \\
\text { и социально значимые } \\
\text { компании, в том числе } \\
\text { связанные с государ- } \\
\text { ством }\end{array}$ & $\begin{array}{l}\text { Зависит от характера } \\
\text { реализуемых мер, но } \\
\text { чаще всего включает } \\
\text { существующие компании }\end{array}$ & $\begin{array}{l}\text { Потенциально широкий, } \\
\text { включающий новые } \\
\text { и существующие инно- } \\
\text { вационные компании, } \\
\text { но на практике весьма } \\
\text { узкий }\end{array}$ \\
\hline $\begin{array}{l}\text { Развиваемые } \\
\text { конкурент- } \\
\text { ные преиму- } \\
\text { щества }\end{array}$ & Локальные & Чаще - локальные & Глобальные \\
\hline $\begin{array}{l}\text { Основные } \\
\text { риски }\end{array}$ & $\begin{array}{l}\text { Поддержка неэффектив- } \\
\text { ных компаний; усиление } \\
\text { отставания }\end{array}$ & $\begin{array}{l}\text { Внедрение продуктов } \\
\text { и технологий, конкурен- } \\
\text { тоспособных только на } \\
\text { внутреннем рынке; воз- } \\
\text { никновение технологи- } \\
\text { ческих разрывов между } \\
\text { смежными отраслями }\end{array}$ & $\begin{array}{l}\text { Ошибка выбора целевых } \\
\text { рынков, технологий или } \\
\text { продуктов; масштабная } \\
\text { поддержка проектов, } \\
\text { результаты которых не } \\
\text { будут востребованы рын- } \\
\text { ком, точечные успехи }\end{array}$ \\
\hline Примеры & $\begin{array}{l}\text { Поддержка системоо- } \\
\text { бразующих компаний, } \\
\text { отчасти - поддержка } \\
\text { автомобилестроения } \\
\text { и импортозамещения }\end{array}$ & $\begin{array}{l}\text { Развитие автомобиле- } \\
\text { строения и фармацев- } \\
\text { тической промышлен- } \\
\text { ности, «Электронная } \\
\text { Россия», поддержка } \\
\text { импортозамещения, } \\
\text { отчасти - развитие } \\
\text { наноиндустрии и цифро- } \\
\text { вая экономика }\end{array}$ & $\begin{array}{l}\text { Национальная техноло- } \\
\text { гическая инициатива, } \\
\text { отчасти - развитие } \\
\text { наноиндустрии и цифро- } \\
\text { вая экономика }\end{array}$ \\
\hline
\end{tabular}

фективных компаний и производств, которые и в дальнейшем также будут нуждаться в поддержке (см., например, (Мау, 2010; Симачев, Кузык, 2012)).

Наиболее востребованной оказалась политика догоняющего развития. Данная политика обычно опирается на уже известные и доказавшие свою эффективность техно- логии и решения, а в некоторых случаях также на апробированные другими странами инструменты и подходы. Все это, однако, не означает, что подобную политику просто реализовать, и что она не предполагает существенных рисков: политика догоняющего развития в общем случае требует одновременных скоординированных изменений в комплексе 
взаимосвязанных отраслей (см. например, (Полтерович, 2016)). Таким образом, данный тип политики предъявляет весьма жесткие требования к системе государственного управления, прежде всего в части сквозного планирования и программирования сдвигов в нескольких смежных отраслях.

Наконец, политика опережающего развития является в современной России наиболее редкой, а обращение государства к ней обычно связано с поиском новых движущих сил долгосрочного роста. Такая политика объективно сопряжена с высоким уровнем неопределенности и предъявляет высокие требования к системе государственного управления, прежде всего в части готовности прекращать неэффективные инициативы и наличия развитых технологических компетенций.

В условиях расширения санкций и ограниченности практических успехов в улучшении бизнес-климата государство неизбежно будет дополнительно обращаться к политике опережающего развития. Такое решение предполагает больший акцент на развитие собственной технологической базы, на поддержку компаний-лидеров, на рукотворное выращивание новых секторов. Однако принципиальная проблема (а может быть, и ловушка) здесь состоит в том, что на определенном этапе реализации политики опережающего развития для достижения значимого экономического эффекта требуется перейти от точечных результатов на уровне отдельных компаний к созданию условий для быстрого распространения новых технологий и перспективных бизнес-моделей в экономике. Фактически потребуется от культуры проектного управления и решения сверхзадач, включающей в том числе запуск изменений в режиме ручного управления и формирование команд с участием чиновников высшего ранга, перейти к культуре качественного исполнения рутин, в том числе связанной с развитием компетенций бюрократии среднего звена и совершенствованием ведомственных вертикалей.

\section{ЛИТЕРАТУРА}

Горст М., Данильцев А., Кузнецов Б., Кузык М., Симачев Ю., Яковлев А. (2009). Оценка антикризисных мер по поддержке реального сектора российской экономики // Вопросъ экономики. № 5. С. 21-46.

Кузнецов Б., Симачев Ю. (2014). Эволюция государственной промышленной политики в России // Журнал Новой экономической ассочиащии. № 2 (22). C. $152-178$.

Мау В. (2010). Экономическая политика 2009 года: между кризисом и модернизацией / / Вопросы экономики. № 1. С. 4-25.

Полтерович В. (2016). Институты догоняющего развития (к проекту новой модели экономического развития России) // Экономические и сочиальнье перемены: факты, тендениии, прогноз. № 5 (47). C. 34-56.

Симачев Ю., Кузык М. (2012). Государственная антикризисная поддержка российских компаний: помощь и ограничения // Журнал Новой экономической ассоииаиии. № 1. C. $100-125$.

Симачев Ю., Кузык М., Кузнецов Б., Погребняк Е. (2014). Россия на пути к новой технологической промышленной политике: среди манящих перспектив и фатальных ловушек // Форсайт. № 8 (4). С. 6-23.

Симачев Ю., Акиндинова Н., Яковлев А. и др. (2018). Структурная политика в России: новые условия и возможная повестка. Науч. рук. Е.Г. Ясин. М.: НИУ ВШЭ.

Chang H.J. (1994). The Political Economy of Industrial Policy. New York: St. Martin's Press.

Garcia Calvo A., Coulter S. (2017). Industrial Transformation in the Aftermath of the Crisis: An Empirical Analysis of industrial Policies in France, Germany, Spain and the United Kingdom. CES Open Forum Series. Vol. 28. Harvard University, Minda de Gunzburg Center for European Studies.

Gual J., Jodar S. (2006). Vertical Industrial Policy in the EU: An Empirical Analysis of 
the Effectiveness of State Aid. EIB Papers 10/2006. European Investment Bank. Economics Department.

Krugman P., Obstfeld M. (1991). International Economics: Theory and Policy. New York: HarperCollins Publishers.

Lin J.Y. (2012). New Structural Economics: A Framework for Rethinking Development and Policy. Washington: The World Bank.

Pack H., Saggi K. (2006). Is There a Case for Industrial Policy? A Critical Survey // World Bank Research Observer. Vol. 21 (2). P. 267-297.

Price C.V. (1981). Industrial Policies in the European Community. London: Macmillan.

Rodrik D. (2004). Industrial Policy for the Twenty-First Century. KSG Working Paper No. RWP04-047. Cambridge, Massachusetts: John F. Kennedy School of Government, Harvard University.

Rodrik D. (2008). Normalizing Industrial Policy. Working Paper No. 3. Washington: The World Bank. The Commission on Growth and Development.

Warwick K. (2013). Beyond Industrial Policy: Emerging Issues and New Trends. OECD Science, Technology and Industry Policy Papers No. 2. Paris: OECD Publishing.

Поступила в редакиию 16.05.2018 2.

\section{REFERENCES}

(with English translation or transliteration)

Chang H.J. (1994). The Political Economy of Industrial Policy. New York: St. Martin's Press.

Garcia Calvo A., Coulter S. (2017). Industrial Transformation in the Aftermath of the Crisis: An Empirical Analysis of Industrial Policies in France, Germany, Spain and the United Kingdom. CES Open Forum Series. Vol. 28. Harvard University, Minda de Gunzburg Center for European Studies.

Gorst M., Danil'tsev A., Kuznetsov B., Kuzyk M., Simachev Y., Yakovlev A. (2009). Evaluation of Anti-Crisis Measures Supporting the Real Sector of the Russian Economy. Voprosy Ekonomiki, 5, 21-46 (in Russian).
Gual J., Jodar S. (2006). Vertical Industrial Policy in the EU: An Empirical Analysis of the Effectiveness of State Aid. EIB Papers 10/2006. European Investment Bank. Economics Department.

Krugman P., Obstfeld M. (1991). International Economics: Theory and Policy. New York: HarperCollins Publishers.

Kuznetsov B., Simachev Yu. (2014). Evolution of State Industrial Policy in Russia. The Journal of the New Economic Association, 2 (22), 152-178 (in Russian).

Lin J. Y. (2012). New Structural Economics: A Framework for Rethinking Development and Policy. Washington: The World Bank.

Mau V. (2010). Economic Policy in 2009: Between the Crisis and Modernization. Voprosy Ekonomiki, 2, 4-25 (in Russian).

Pack H., Saggi K. (2006). Is There a Case for Industrial Policy? A Critical Survey. World Bank Research Observer, 21 (2), 267-297.

Polterovich V. (2016). Institutions of Catching-up Development (On the Project of a New Model for Economic Development of Russia). Economic and Social Changes: Facts, Trends, Forecast, 47, 34-56 (in Russian).

Price C.V. (1981). Industrial Policies in the European Community. London: Macmillan.

Rodrik D. (2004). Industrial Policy for the Twenty-First Century KSG Working Paper No. RWP04-047. Cambridge, Massachusetts: John F. Kennedy School of Government, Harvard University.

Rodrik D. (2008). Normalizing Industrial Policy. Working Paper No. 3. Washington: The World Bank. The Commission on Growth and Development.

Simachev Y., Akindinova N., Yakovlev A. et al. (2018). Industrial Policy in Russia: New Conditions and Possible Agenda. Scientific head E.G. Yasin. Moscow: NRU Higher School of Economics (in Russian).

Simachev Y., Kuzyk M. (2012). The State Anti-Crisis Support of Russian Companies: Assistance and Restrictions. The Journal of the New Economic Association, 1 (13), 100-125 (in Russian). 
Simachev Y., Kuzyk M., Kuznetsov B., Pogrebnyak E. (2014). Russia Heading Towards a New Technology-Industrial Policy: Exciting Prospects and Fatal Traps. Foresight-Russia, 8, 4, 6-23 (in Russian).
Warwick K. (2013). Beyond Industrial Policy: Emerging Issues and New Trends. OECD Science, Technology and Industry Policy Papers, No. 2. Paris: OECD Publishing.

Received 2.02.2018

\section{Y.V. Simachev}

National Research University Higher School of Economics, Moscow, Russia

\section{M.G. Kuzyk}

National Research University Higher School of Economics: Interdepartmental Analytical Center, Moscow, Russia

\section{E. V. Pogrebnyak}

Vnesheconombank, Moscow, Russia

\section{Federal Industrial Policy: Basic Models and Russian Practice ${ }^{6}$}

Abstract. The article typologies the Russian industrial policy of the 2000s, discusses major initiatives in this area, as well as changes in the state's approach to the industrial policy. The tendency of the state to implement vertical policy is noted; while horizontal mechanisms are often "verticalized" under the influence of traditional interest groups. The state actively initiates new support measures, especially in crises and at the same time seldom terminates some existing ineffective instruments. In the period under review, the state more often appealed to the policy of catching-up development. In modern conditions, the government is likely to make significant efforts to implement the policy of breakthrough development. For the success of such a policy, it will be necessary to move in time from supporting local achievements of individual companies to creating conditions for the fast spread of new technologies and promising business models. In turn, this requires a transition of state governance from a culture of project management to a culture of quality execution of routines.

Keywords: industrial policy; structural changes; state support; catching-up development; breakthrough development.

JEL Classification: L52, O25.

DOI: $10.31737 / 2221-2264-2018-39-3-8$

\footnotetext{
6 The article is based on some results of the HSE research project "Structural Changes in the Russian Economy and Industrial Policy" (https://www.hse.ru/data/2018/04/13/1150725828/Аналитический доклад по структурной политике.pdf).
} 